Full length article

\title{
Solution blow spinning fibres: New immunologically inert substrates for the analysis of cell adhesion and motility
}

\author{
Rafaella T. Paschoalin ${ }^{\mathrm{a}, \mathrm{b}}$, Bruna Traldi a , Gülcan Aydin ${ }^{\mathrm{c}}$, Juliano E. Oliveira ${ }^{\mathrm{d}}$, Stephan Rütten ${ }^{\mathrm{e}}$, \\ Luiz H.C. Mattoso ${ }^{\mathrm{a}, \mathrm{b}, *}$, Martin Zenke ${ }^{\mathrm{c}}$, Antonio Sechi ${ }^{\mathrm{c}, *}$ \\ a National Nanotechnology Laboratory for Agribusiness (LNNA), Embrapa Instrumentation, 13560-970 São Carlos, SP, Brazil \\ ${ }^{\mathrm{b}}$ Department of Chemistry, Federal University of São Carlos (UFSCar), 13565-905 São Carlos, SP, Brazil \\ ' Institute of Biomedical Engineering, Dept. of Cell Biology, Uniklinik RWTH Aachen, Pauwelsstrasse, 30, D-52074 Aachen, Germany \\ ${ }^{\mathrm{d}}$ Department of Engineering, Materials Engineering, Federal University of Lavras (UFLA), 37200-000 Lavras, MG, Brazil \\ e Electron Microscopy Facility, Uniklinik RWTH Aachen, Pauwelsstrasse, 30, D-52074 Aachen, Germany
}

\section{A R T I C L E I N F O}

Article history:

Received 13 July 2016

Received in revised form 16 December 2016

Accepted 5 January 2017

Available online 7 January 2017

\section{Keywords:}

Solution blow spinning

Dendritic cells

Cell motility

Cytoskeleton

\begin{abstract}
A B S T R A C T
The control of cell behaviour through material geometry is appealing as it avoids the requirement for complex chemical surface modifications. Significant advances in new technologies have been made to the development of polymeric biomaterials with controlled geometry and physico-chemical properties. Solution blow spinning technique has the advantage of ease of use allowing the production of nano or microfibres and the direct fibre deposition on any surface in situ. Yet, in spite of these advantages, very little is known about the influence of such fibres on biological functions such as immune response and cell migration. In this work, we engineered polymeric fibres composed of either pure poly(lactic acid) (PLA) or blends of PLA and polyethylene glycol (PEG) by solution blow spinning and determined their impact on dendritic cells, highly specialised cells essential for immunity and tolerance. We also determined the influence of fibres on cell adhesion and motility. Cells readily interacted with fibres resulting in an intimate contact characterised by accumulation of actin filaments and focal adhesion components at sites of cell-fibre interactions. Moreover, cells were guided along the fibres and actin and focal adhesion components showed a highly dynamic behaviour at cell-fibre interface. Remarkably, fibres did not elicit any substantial increase of activation markers and inflammatory cytokines in dendritic cells, which remained in their immature (inactive) state. Taken together, these findings will be useful for developing new biomaterials for applications in tissue engineering and regenerative medicine.
\end{abstract}

(c) 2017 Acta Materialia Inc. Published by Elsevier Ltd. All rights reserved.

\section{Introduction}

The development of novel biomaterials and their use in biomedicine has received much attention in recent years [1,2]. Nanofibres have a wide medical application, ranging from scaffolds for tissue regeneration to drug delivery systems. Based on the type of application, significant advances in new technologies have been made to the development of polymeric biomaterials with controlled geometry and physico-chemical properties. Since the 1990s there has been an increasing interest in methods for polymeric fibres production, such as electrospinning [3]. Recently,

\footnotetext{
* Corresponding authors at: National Nanotechnology Laboratory for Agribusiness (LNNA), Embrapa Instrumentation, 13560-970 São Carlos, SP, Brazil (L.H.C. Mattoso). Institute of Biomedical Engineering, Dept. of Cell Biology, Uniklinik RWTH Aachen, Pauwelsstrasse, 30, D-52074 Aachen, Germany (A. Sechi)

E-mail addresses: luiz.mattoso@embrapa.br (L.H.C. Mattoso), antonio.sechi@rwth-aachen.de (A. Sechi).
}

nanometric fibres from a variety of polymers, including polyvinyl chloride (PVC), nylon-6, poly(lactic acid) (PLA) and poly(D, L-lactic acid) (PDLLA) have been produced by another method known as solution blow spinning (SBS) [4-11]. This innovative technique is conceptually similar to electrospinning but does not require a high voltage and, therefore, it is much safer and simpler. Additionally, it allows fast fibre production and versatility in solvent choice [4]. In contrast to other methods, SBS techniques enable the deposition of fibres directly onto any type of surface, including living systems as in the case of surgical scaffolds, sealants or tissue adhesives $[4,9,11]$. Nanofibres scaffolds fabricated by SBS have been shown to support osteogenic differentiation of human bone marrow stromal cells [10] and prevent both bacterial attachment and thrombosis [11].

Despite the promise of such techniques, their ultimate functional success to new medical therapies depends on how cells respond to the nanostructured biomaterials obtained. One main 
strategy in tissue engineering involves the generation of hybrid structures containing biomaterials and cells. Biomaterials provide the initial support structure for cells to organise and assemble themselves into a functioning tissue. Hence, biomaterials must be highly adaptable polymers that can be easily engineered to achieve topographic and physico-chemical properties to be able to mimic native microenvironments required for the regulation of cell function and fate [12]. In addition, the biomaterial must be biocompatible enough not to elicit host immune response [13-17]. Many polymers have been used in the attempt to produce such microenvironments including, poly-L-lactic acid (PLLA), polyglycolic acid (PGA) and poly-lactic-co-glycolic acid (PLGA). Although it was found that these materials could be easily used to fabricate various architectures with controlled degradation characteristics, they also caused unwanted effects including activation of immune cells thus potentially leading to their rejection $[15,18-22]$. Hence, to avoid host reactions and improve implant safety, it is essential to understand how cells of various origin including immune cells interact with biomaterials and how these interactions may prove pivotal to evaluate the material biocompatibility.

This work was centred on the fabrication and characterisation of polymeric fibres composed of pure PLA or various PLA/PEG blends by solution blow spinning technique. Cells easily interacted with SBS fibres resulting in an intimate contact characterised by accumulation of actin filaments and focal adhesion components at sites of cell-fibre interactions. Moreover, cells movement was guided along SBS fibres and actin and focal adhesion components showed a highly dynamic behaviour at cell-fibre interfaces. Finally, SBS fibres did not elicit any substantial increase of activation markers and inflammatory cytokines in dendritic cells, which remained in their immature (inactive) state. Our findings suggest that SBS fibres could serve as novel inert biomaterials for tissue engineering applications.

\section{Materials and methods}

\subsection{Chemicals}

Poly(lactic acid) (PLA, mol. wt., 76,000) and polyethylene glycol (PEG, mol. wt., 8000) were purchased from Biomater, Ltda (São Carlos, Brazil) and Sigma-Aldrich (Brazil), respectively. Chloroform and acetone were purchased from Sigma-Aldrich and were not subjected to purification processes.

\subsection{Preparation of polymer solutions}

Five samples were prepared composed of pure PLA or PLA/PEG blends at PLA:PEG ratios of 99:1, 95:5, 90:10 or 80:20 (w/w). The overall polymer concentration was maintained constant at $12 \%$ for all blends. Polymer solutions were prepared by solubilizing weighed portions of the two chemicals in chloroform:acetone $(3: 1 \mathrm{v} / \mathrm{v})$ with stirring at room temperature for $3 \mathrm{~h}$. The polymer solutions were transferred into $25 \mathrm{~mL}$ glass syringes (Becton Dickinson, USA) and placed in a syringe pump (SBS apparatus).

\subsection{Solution blow spinning (SBS) apparatus}

The SBS apparatus was composed of a polymer injection pump (NE-1010-US One Channel 100 lb.), a collector consisting of a spinning cylinder positioned horizontally, a source of compressed air and a concentric nozzle system with an inner nozzle $0.5 \mathrm{~mm}$ in diameter) through which the polymer solution is injected at a rate of $7.2 \mu \mathrm{L} / \mathrm{min}$ and an outer nozzle through which compressed air is delivered at a constant pressure of $2.4 \mathrm{kPa}$. The inner nozzle was positioned so that it protruded $2 \mathrm{~mm}$ from the outer nozzle. SBS fibres were deposited directly on the collector spinning at $180 \mathrm{rpm}$ that was positioned at a fixed working distance of $18 \mathrm{~cm}$ from the nozzle system. SBS fibre production was done at $21{ }^{\circ} \mathrm{C}$ and $35 \%$ humidity.

\subsection{Rheological analysis}

Viscosity of PLA and PLA/PEG blends was determined using the rotational and oscillatory Rheometer MCR 302 (Anton Paar, Austria). Measurements were done with a concentric cylinder geometry (DG26.7/Q1) in rotational mode at $25^{\circ} \mathrm{C}$ using a shear rate between 1 and $100 \mathrm{~s}^{-1}$.

\subsection{PEG dissolution analysis}

To determine the release of PEG from PLA/PEG SBS fibres, fibres were incubated with $\mathrm{PBS}$ ( $\mathrm{pH} 7.2$ ) or cell culture medium at $37^{\circ} \mathrm{C}$ for up to $48 \mathrm{~h}$ in a shaking water bath (shaking speed: $150 \mathrm{rpm}$ ). Samples were collected at 2, 6, 12, 24 and $48 \mathrm{~h}$, washed with distilled water and dried in a vacuum oven at room temperature for $24 \mathrm{~h}$. Dried samples were analysed by infrared spectroscopy. For quantifying PEG dissolution, each spectrum baseline was corrected by subtracting a background absorbance calculated from the absorbance value between 2800 and $3100 \mathrm{~cm}^{-1}$. Afterwards, each spectrum was normalised as already described [23] and then the intensity ratio blends/PLA for the $2800 \mathrm{~cm}^{-1}$ peak was determined.

To determine the loss of PEG from SBS fibres, we used 80:20 fibres due to their high content of PEG that allows more precise measurements. Dried SBS fibre mats $(2.5 \times 2.5 \mathrm{~cm})$ were weighed, placed in a vial filled with $15 \mathrm{~mL}$ phosphate-buffered saline (PBS) (pH 7.0; Invitrogen Life Technologies) or cell culture medium supplemented with $10 \%$ FCS and then incubated with constant shaking (150 rpm) at $37^{\circ} \mathrm{C}$ for 4,8 or $12 \mathrm{~h}$. At these time intervals, triplicate specimens were collected, rinsed thoroughly with distilled water and dried under vacuum to constant weight at room temperature. The percentage of elution was denoted as weight loss (\%)= $\left(W_{0}-W_{t}\right) / W_{0} \times 100$, where $W_{0}$ was the dry weight before incubation and $W_{t}$ was the dry weight at time $t$. The percentage of PEG elution was corrected by taking into account PLA mass loss.

\subsection{Infrared spectroscopy}

Infrared spectra were collected on dried samples using the attenuated total reflectance (ATR) method with a spectrophotometer (Vertex 70, Bruker, Germany). Spectra were collected for all samples at a resolution of $2 \mathrm{~cm}^{-1}$ in the range between 3300 and $600 \mathrm{~cm}^{-1}$ for a total of 128 scans.

\subsection{Thermal properties}

The thermal transition of pure PLA and PLA/PEG blends was measured under nitrogen at a flow rate of $20 \mathrm{~mL} / \mathrm{min}$ using a differential scanning calorimeter (DSC; TA Instruments calorimetric analyser, model Q100, New Castle, USA). DSC measurements were done using 5-6 $\mathrm{mg}$ for each sample, which were sealed in an aluminium pan and heated from 0 to $180^{\circ} \mathrm{C}$ at a rate of $10^{\circ} \mathrm{C} / \mathrm{min}$.

Glass transition temperature $\left(T_{g}\right)$, cold crystallization temperature $\left(T_{c c}\right)$, melting temperature $\left(T_{m}\right)$, and degree of crystallinity $\left(\chi_{c}\right)$ were determined from the first heating cycle to observe the effect of SBS processing. $T_{g}$ was taken at the mid-point of heat capacity changes, $T_{m}$ at the peak value of the endotherms and the enthalpy was calculated from area under the curve. All parameters were calculated by the software used to drive the DSC calorimeter. The degree of crystallinity $\left(\chi_{c}\right)$ of PLA and PLA/PEG 
blends was calculated based on the enthalpy value of a $100 \%$ crystalline PLA as described in Eq. (1). The enthalpy of fusion for pure PLA crystal is $93 \mathrm{~J} / \mathrm{g}$ [24].

$\chi_{c}^{P L A},(\%)=\left[\left(\Delta H_{m}^{P L A}-\Delta H_{c c}^{P L A}\right) /\left(\Delta H_{m}^{P L A, 0} \times W^{P L A}\right)\right] \times 100$

where $\Delta H_{m}^{P L A}$ is PLA enthalpy of fusion in the fibres, $\Delta H_{c c}^{P L A}$ is the enthalpy corresponding to the temperature of cold crystallization, $\Delta H_{m}^{P L A, 0}$ is the enthalpy of fusion, when the polyester is in $100 \%$ crystalline state $\left(\Delta H_{m}^{P L A, 0}=93 \mathrm{~J} / \mathrm{g}\right)$ and $W^{P L A}$ is the mass fraction of PLA in SBS fibre mats.

\subsection{Water contact angle measurements}

Water contact angle measurements were done using a CAM 101 optical contact angle meter (KSV Instruments, Monroe, USA) equipped with a CCD camera (KGV-5000). Six drops of distilled water $(2 \mu \mathrm{L})$ were randomly placed onto the fibre surface and the water contact angle was determined at room temperature. Temporal images of the droplet were taken after $5 \mathrm{~s}$ and contact angles were calculated by computer analysis using the software KGV500 . Water contact angle for the different SBS fibres was expressed as the mean value $( \pm S D)$ of all measurements. To determine whether incubation of SBS fibres with PBS or cell culture media influences their hydrophilicity, fibres were incubated with PBS or DMEM supplemented with $10 \%$ fetal calf serum (FCS) at $37{ }^{\circ} \mathrm{C}$ for $24 \mathrm{~h}$. Following incubation, fibres were washed with distilled water and dried in a vacuum oven at room temperature for $24 \mathrm{~h}$ and the water contact angle was determined as described above.

\subsection{Cell culture and transfection}

B16F1 cells (ATCC CRL 6323) were grown at $37{ }^{\circ} \mathrm{C}, 5 \% \mathrm{CO}_{2}$ in DMEM high glucose supplemented with $10 \%$ fetal calf serum (FCS), $2 \mathrm{mM}$ L-glutamine, $1 \mathrm{mM}$ sodium pyruvate, $100 \mu \mathrm{g} / \mathrm{ml}$ streptomycin, and $100 \mathrm{U} / \mathrm{ml}$ penicillin as already described [25]. Stable expression of RFP-actin or RFP-zyxin in B16F1 cells was obtained by viral-mediated gene delivery as already described [26]. Infected B16F1 cells were sorted by FACS to obtain pure cell populations expressing RFP-actin or RFP-zyxin.

Murine dendritic cells were generated from bone marrow progenitor cells isolated from mouse hind legs as already described [15]. Briefly, bone marrow progenitor cells were cultured at a density of $2 \times 10^{6}$ cells/mL in RPMI 1640 medium supplemented with $10 \%$ FCS, $2 \mathrm{mM}$ L-glutamine, $100 \mu \mathrm{g} / \mathrm{mL}$ streptomycin, $100 \mathrm{U} / \mathrm{mL}$ penicillin (all from Invitrogen Life Technologies, Germany), $50 \mathrm{mM}$ 2-mercaptoethanol, recombinant murine SCF $(100 \mathrm{ng} / \mathrm{mL})$, $25 \mathrm{ng} / \mathrm{mL}$ Flt3 ligand (PeproTech, Germany), $40 \mathrm{ng} / \mathrm{mL}$ recombinant long-range IGF-1 (Sigma-Aldrich, Germany), $5 \mathrm{ng} / \mathrm{mL}$ rIL-6/ soluble IL-6R fusion protein (hyper-IL-6; kindly provided by S. Rose-John), $20 \mathrm{U} / \mathrm{mL}$ recombinant mouse GM-CSF and $1 \mathrm{mM}$ dexamethasone. At day 7 of culture, BMPCs were differentiated into DCs using the above medium supplemented only with $250 \mathrm{U} / \mathrm{mL}$ recombinant murine GM-CSF. Dendritic cells were activated with $1 \mu \mathrm{g} / \mathrm{mL}$ lipopolysaccharides (LPS) from Escherichia coli 0127:B8 (Sigma-Aldrich, Germany) for 24 or $48 \mathrm{~h}$.

\subsection{Scanning electron microscopy}

Fibre morphology and size were analysed by scanning electron microscopy (SEM) using a JEOL scanning electron microscope (model JSM-6510/GS) at $10 \mathrm{kV}$ with a $10 \mathrm{~mm}$ working distance. Samples were sputter coated with gold using a sputter coater. The diameter of the fibre was measured from SEM photographs using ImageJ (available at http://rsb.info.nih.gov/ij; developed by Wayne Rasband, National Institutes of Health, Bethesda, MD).
SBS fibre mat porosity was measured from three (for each SBS fibre type) representative SEM images using the ND ImageJ plugin [27] and expressed as the fraction of the total area not occupied by SBS fibres.

Scanning electron microscopy analysis of dendritic cells and B16F1 cells was done as previously described $[25,26]$. Specifically, dendritic cells and B16F1 cells were fixed with 3\% glutaraldehyde (Agar Scientific, Stansted, United Kingdom) in Soerensen's phosphate buffer (Merck, Darmstadt, Germany) for $1 \mathrm{~h}$ at room temperature. After washing with Soerensen's phosphate buffer for $15 \mathrm{~min}$, samples were dehydrated through an ascending ethanol series (30\%, 50\%, 70\% and 95\%, 10 min each) with a final incubation in $100 \%$ ethanol for $10 \mathrm{~min}$ (repeated 3 times). Drying of the samples was done in hexamethyldisilazane (Sigma-Aldrich, Germany) for 20 min at room temperature, followed by sputter coating to generate a 10-nm gold layer (Sputter Coater EM SCD500, Leica, Wetzlar, Germany). Samples were examined with a digital scanning electron microscope (ESEM XL30 FEG; FEI, Eindhoven, The Netherland) using a working distance of $8 \mathrm{~mm}$ and an acceleration voltage of $5 \mathrm{kV}$. Electron microscopy images were processed using Photoshop 13.0 (Adobe Systems, Inc., USA).

\subsection{Determination of the expression of surface markers in dendritic cells}

Immature dendritic cells $\left(5 \times 10^{5}\right)$ were incubated on $15 \mathrm{~mm}$ biomaterial disks at $37^{\circ} \mathrm{C}, 5 \% \mathrm{CO}_{2}$ for $24 \mathrm{~h}$ or $48 \mathrm{~h}$. Dendritic cells seeded on empty wells (without fibres) served as negative controls. Afterwards, cells were gently removed from biomaterial surface, collected and washed with FACS buffer (PBS supplemented with $0.5 \%$ FCS and $2 \mathrm{mM}$ EDTA). Approximately $1 \times 10^{6}$ cells were resuspended in $50 \mu \mathrm{L}$ FACS buffer and incubated with the selected antibodies for $30 \mathrm{~min}$ at $4{ }^{\circ} \mathrm{C}$. Following incubation, cells were washed with $2 \mathrm{~mL}$ of FACS buffer and re-suspended in $200 \mu \mathrm{L}$ FACS buffer and kept on ice. The expression of dendritic cells surface proteins (MHCII, CD40, CD80 and CD86) was analysed by flow cytometry using a FACS Canto II (BD Bioscience, Germany). The compensation was done either manually or using automatic instrument settings. Data were collected on 50.000 viable cells and analysed using FlowJo software (FlowJo, LLC, USA).

\subsection{RNA isolation, reverse transcription and cytokine expression analysis}

RNA isolation and cDNA synthesis was performed as previously described [15]. Expression of the cytokines IL-1 $\beta$, IL-6, IL-10, IL$12 \mathrm{p} 40, \mathrm{TNF} \alpha$ and RANTES was determined by PCR (Thermocycler, Eppendorf, Hamburg, Germany) using specific primers ( $1 \mu \mathrm{g} / \mathrm{each}$ in $10 \mu \mathrm{L}$, see [15] for primers' technical data). As the positive control, immature dendritic cells were treated with $1 \mu \mathrm{g} / \mathrm{mL}$ LPS for $24 \mathrm{~h}$. For quantification, intensity of gel bands from three independent experiments was determined using the 1D gel electrophoresis image analysis software Gel Analyzer (http://www.gelanalyzer.com) using automatic band detection and background subtraction. Intensity values for each band were normalised using GAPDH expression levels.

\subsection{Immunofluorescence and video microscopy}

Immunofluorescence and video microscopy was done as already described $[25,26,28]$. Cells were fixed with $4 \%$ paraformaldehyde (in PBS) for $30 \mathrm{~min}$. at RT. After washing twice with PBS, the cell membrane was permeabilised with $0.1 \%$ Triton $\mathrm{X}-100$ (in PBS) for $1 \mathrm{~min}$ at RT. The actin cytoskeleton was labelled with Alexa 594-conjugated phalloidin (Molecular Probes, Eugene, USA; $1: 500$ in $1 \%$ BSA/TBS for 30 min at RT), for vinculin labelling, 
cells were labelled using an anti-vinculin antibody (hVin1, Sigma; $1: 100$ in $1 \%$ BSA/TBS for $30 \mathrm{~min}$ at RT) followed by Alexa 488conjugated goat anti-mouse IgG (Molecular Probes, Eugene, USA; $1: 500$ in $1 \% \mathrm{BSA} / \mathrm{TBS}$ for $30 \mathrm{~min}$ at RT). Nuclei were labelled using Hoechst (Sigma; 1:1000 in 1\% BSA/TBS for 30 min at RT). For live cell imaging, cells were seeded on SBS fibres at a concentration of $2 \times 10^{4}$ cells $/ \mathrm{mL}$ (dendritic cells) or $6 \times 10^{3}$ cells $/ \mathrm{mL}$ (B16F1). Images were acquired using an Axiovert 200 microscope (Carl Zeiss, Germany) equipped with a Plan-Apochromat 100x/1.30 NA (or 63x/1.30 NA) objective and a CCD camera (Cascade 512B; Princeton Instruments, Trenton, USA) driven by IPLab Spectrum software (Scanalytics, Fairfax, USA). During image acquisition, cells were maintained at $37^{\circ} \mathrm{C}$ and $5 \% \mathrm{CO}_{2}$ using a heating stage and $\mathrm{CO}_{2}$ controller, respectively (PeCon $\mathrm{GmbH}$, Germany). Phase contrast, RFP-actin and RFP-zyxin images were acquired every 7-8 s. Digital handling of the images was done using IPLab Spectrum, ImageJ and Adobe Photoshop 13.0 (Adobe Systems, Inc., USA).

\subsection{Statistical analysis}

All graphs and statistical analyses were done using Prism 5.0 (GraphPad Software Inc., CA). In box and whisker plots, lines in the middle of the boxes indicate medians; top of the boxes indicates the 75th quartile whereas bottom of the boxes indicates the 25th quartile. Whiskers represent the 10th (lower) and 90th (upper) percentile. For FACS and RT-PCR experiments statistical significance was tested using two-tailed Mann-Whitney nonparametric $U$ test and two-way ANOVA, respectively. Sample pairs were considered different when $p<0.5$.

\section{Results}

\subsection{Development and characterisation of SBS fibres}

We have previously shown that solution blow spinning is a simple yet powerful technique to fabricate micro- and nanofibres $[4,6]$ that allows rapid fibre deposition onto any substrate. In this work, we fabricated PLA and PLA/PEG fibres and analysed their morphology and size (diameter) distribution by scanning electron microscopy (Fig. 1A). Although the geometry of all SBS fibres was similar, their diameter was affected by the concentration of PEG resulting in an inverse correlation between SBS fibre diameter and PEG amount (Fig. 1A, B). The influence of PEG on PLA/PEG fibre diameter could be attributed to the fact that polymer solutions containing PEG had lower viscosities under a range of shear rates between 1 and $100 \mathrm{~s}^{-1}$ (Fig. 1C). As a consequence, PLA/PEG polymer solution will flow through the nozzle at higher speed resulting in more stretched, thinner SBS fibres.

Analysis of SBS fibre mat porosity showed similar values for SBS fibre containing 1,5 or $10 \%$ PEG, whereas pure PLA SBS fibres and fibres containing $20 \%$ PEG had slightly lower and higher porosity, respectively (Fig. 1A_SUP). It is important to note that, due to random fibre deposition on the collector, spaces within fibre mats will not be in the same range for each fibre preparation of a given SBS type. Hence, care should be taken when interpreting these data as suggested also by the controversy regarding methodologies, variance and meaning of fibre mat porosity $[10,29,30]$.

The chemical composition of native PLA or PLA/PEG SBS fibres was determined by attenuated total reflection Fourier transform infrared (ATR-FTIR) spectroscopy (Fig. 1D and Table 1_SUP). For PLA and PLA/PEG blends, the band assignments and positions are in agreement with the literature [31]. For PLA, the bands at 2994 and $2944 \mathrm{~cm}^{-1}$ are due to the $\mathrm{C}-\mathrm{H}$ stretching vibration of $-\mathrm{CH}_{3}$ and $-\mathrm{CH}$ groups. The sharp peak at $1751 \mathrm{~cm}^{-1}$ is assigned to the stretching vibration of ester carbonyl group. In the spectrum of
PLA and PLA/PEG blends, all of these typical transmittance bands of PLA polymer are detected (see Table 1_SUP). Most of the bands associated with PLA and PEG are partially overlapped in the spectra. Furthermore, the characteristic of $\mathrm{CH}$ stretching from PEG $2880 \mathrm{~cm}^{-1}$ was also detected confirming the presence of the two components in the blends (inset in Fig. 1D).

To further characterise the physical-chemical properties of SBS fibres, we determined their degree of hydrophilicity by water contact angle measurements according to Young's equation. Native pure PLA SBS fibres were hydrophobic (Fig. 1E). Interestingly, addition of just $1 \%$ PEG sensibly reduced the water contact angle and further increasing the amount of PEG led to an almost linear decrease of the water contact angle, which was about $95^{\circ}$ for SBS fibres containing $20 \%$ PEG (Fig. 1E). These observations clearly indicate that native SBS fibres composed of PLA/PEG blends are more hydrophilic than pure PLA SBS fibres.

Because in potential clinical applications SBS fibres would be in contact with biological fluids, we sought to determine whether incubation of SBS fibres with PBS (representative for isotonic conditions) or cell culture media (recapitulate extracellular tissue fluids) influences their hydrophilicity. Notwithstanding fibre composition, the exposure of SBS fibres to PBS or cell culture media caused a reduction of their hydrophilicity as shown by the increase of the water contact angle to values similar to those of pure PLA (Fig. 1E). Remarkably, under the same conditions, we also observed a reduction of the peak intensity at $2880 \mathrm{~cm}^{-1}$ (representative of PEG presence) (Fig. 1F). Accordingly, we found that PEG was quickly released during the first $12 \mathrm{~h}$ of incubation with either PBS or cell culture media (Fig. 1B_SUP). Together, these data suggest that a portion of the more hydrophilic PEG on fibre surface was lost possibly due to its solubility in water [32].

Finally, we characterised SBS fibre mat thermal properties by differential scanning calorimetry (DSC). Pure PLA SBS fibres displayed a glass transition temperature $\left(T_{g}\right)$ at $61^{\circ} \mathrm{C}$, an exothermic peak of cold crystallization $\left(T_{c c}\right)$ at $111^{\circ} \mathrm{C}$ and an endothermic melting peak $\left(T_{m}\right)$ at $147^{\circ} \mathrm{C}$ (Fig. $1 \mathrm{G}$ and Table 2_SUP). PEG addition did not greatly affect $T_{m}$ for PLA (Table 2_SUP). For PLA/PEG blends, the melting peak of PEG was about $54{ }^{\circ} \mathrm{C}$, whereas $T_{g}$ could not be interpreted due to very high overlap with $T_{g}$ of pure PLA (Fig. 1G). Importantly, higher PEG content led to a clear decrease of $T_{c c}$ to values between $99^{\circ} \mathrm{C}$ and $67^{\circ} \mathrm{C}$ and increase of crystallinity from 2 to 17\% (Fig. 1G and Table 2_SUP). These findings are in line with previous studies and suggest that PEG acts like a nucleating agent for PLA [33,34]. Furthermore, PEG has been shown to be a suitable plasticizer or impact modifier for PLA owing to its good miscibility with PLA [32,35-37]. Thus, despite the difficulty in determining $T_{g}$ for PLA/PEG blends, the clear concomitant $T_{c c}$ decrease and crystallinity increase suggest that PEG was well harmonised with PLA physico-chemical features in our SBS fibres.

\subsection{Morphology and interaction of dendritic cells and B16F1 cells with SBS fibres}

In light of the potential application of SBS fibres in biological and clinical contexts such as tissue engineering, an essential condition is that cells interact with SBS fibres and respond to fibre topographic features. For this purpose, we chose two cell types: B16F1 cells and dendritic cells. B16F1 cells represent a very well established model for studying the molecular basis of cell adhesion and motility $[17,25,38,39]$ two important requirements for successful tissue engineering. Dendritic cells, in addition to be highly motile [40], play a fundamental role in the regulation of the immune response $[41,42]$ and serve as an important system for testing also the potential immunological reactivity of SBS fibres in vitro (see below). 

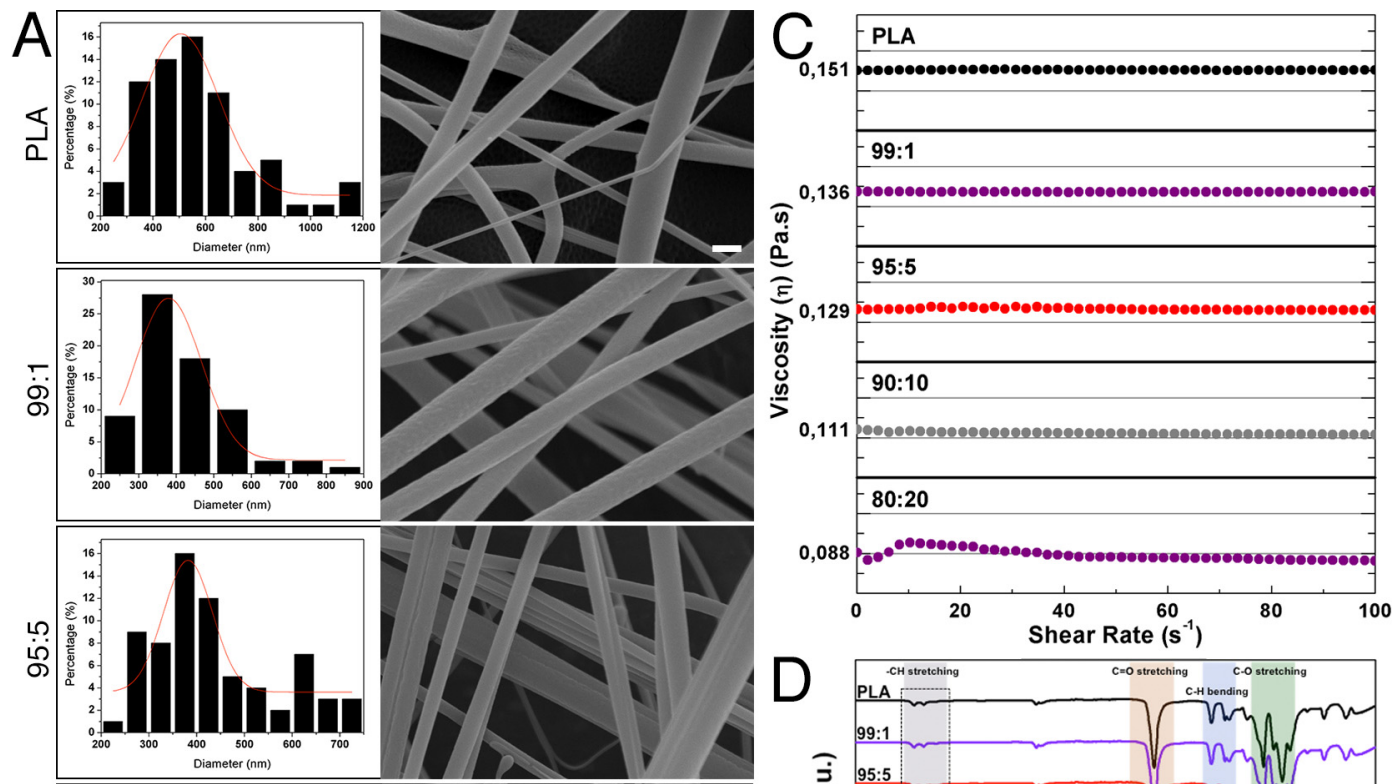

D
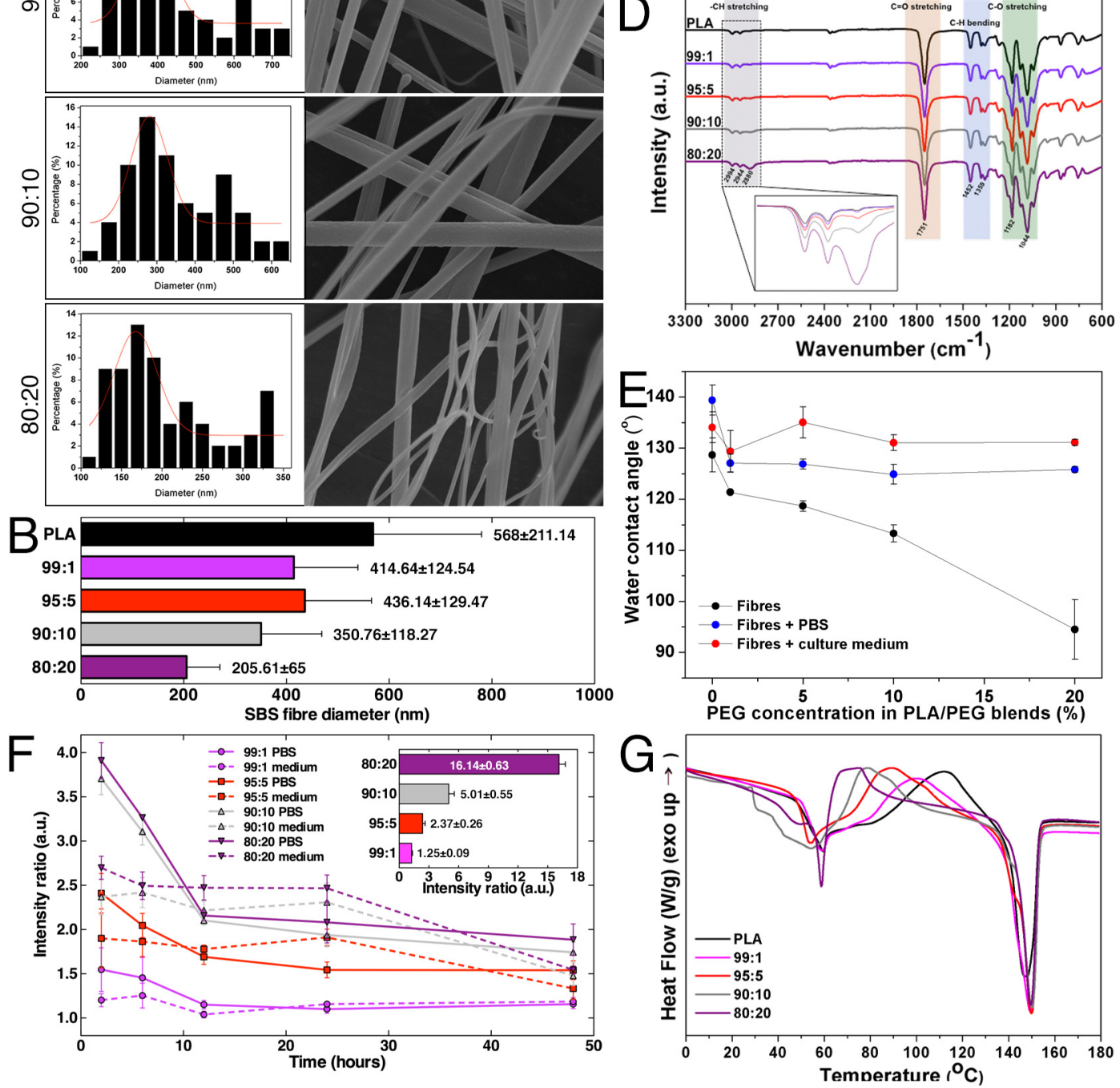



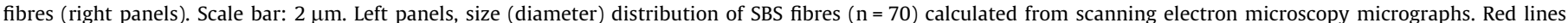





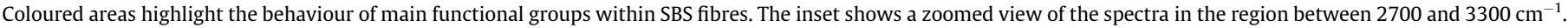

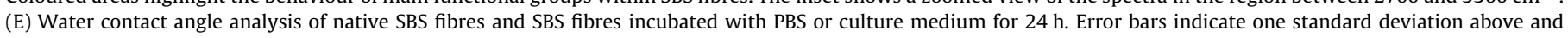

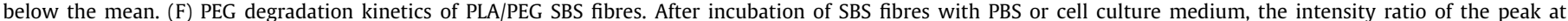

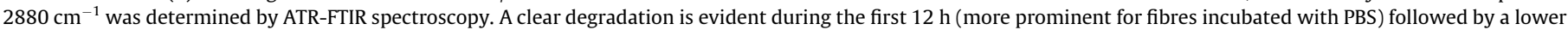

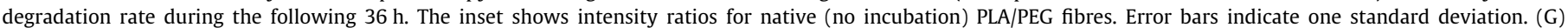

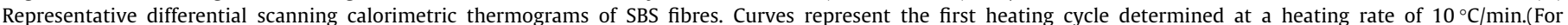
interpretation of the references to colour in this figure legend, the reader is referred to the web version of this article.) 
We initially seeded dendritic cells and B16F1 cells on pure PLA fibres or fibres composed of various PLA/PEG blends for $24 \mathrm{~h}$, fixed and analysed them by scanning electron microscopy (SEM). Regardless of the type of fibres, a common feature of B16F1 and dendritic cells is that they interacted very tightly with one or more adjacent SBS fibres (Fig. 2). In particular, dendritic cells retained their round morphology characterised by several peripheral lamellipodia-like cellular extensions, which bound to SBS fibres (Fig. 2A-E). By contrast, B16F1 cells on SBS fibres lost their typical fan-like shape $[17,25]$ acquiring an elongated morphology. Also in this case, cells bound to SBS fibres via cellular extensions (Fig. $2 \mathrm{~F}$ $0)$. In no case, we observed signs of toxicity in cells exposed to SBS fibres. These observations clearly indicate that cells readily interact with various types of SBS fibres and respond to their topography.

\subsection{Distribution of actin cytoskeleton and focal adhesion components} in dendritic cells and B16F1 cells bound to SBS fibres

Next, we determined whether the tight interaction of dendritic cells and B16F1 cells with SBS fibres was associated with concentration of actin filaments and focal adhesion components at cellfibre interfaces. To achieve this goal, dendritic cells and B16F1 cells were plated on SBS fibres for $24 \mathrm{~h}$, fixed and labelled with fluorescent phalloidin (to visualise actin filaments) or an antibody against vinculin (an essential focal adhesion protein). As expected, we observed a prominent accumulation of actin filaments at the site of contact between dendritic cells and SBS fibres (Fig. 3A-E). Since dendritic cell cellular projections often surrounded SBS fibres almost completely around their circumference, actin accumulation resembled two parallel tracks (corresponding to opposite fibre sites) in wide field fluorescence microscopy images (arrows in Fig. 3A, B, D and E). Consistent with these observations, we found that also vinculin accumulated in a comparable spatial manner at cell-fibre interaction sites (Fig. 2SUP). Given the similar phenotypic interaction of B16F1 cells with SBS fibres (see SEM images above), we expected a similar spatial distribution of actin and vinculin at cell-fibre interfaces. As shown in Figs. 4 and 3SUP, actin and vinculin accumulated at these locations regardless of the type of SBS fibre (arrows in Fig. 4). Collectively, these findings indicate that the tight interaction between cells and SBS fibres induces the redistribution of actin and vinculin at cell-fibre interfaces.

\subsection{SBS fibres function as tracks for cell motility}

A fundamental property of cells is their ability to move. Cell motility is essential for embryo development, wound healing and immune response. In the latter case, dendritic cells play a major role given their ability to migrate to peripheral organs and then, following antigen uptake, to home to lymphoid tissues [42]. In the context of tissue regeneration, the ability of biomaterials to guide cell migration $[16,17,43,44]$ could support a faster and a more efficient healing process. Our findings above showing that actin and focal adhesion components are redistributed to cellfibre interfaces suggest an active actin cytoskeleton remodelling, an essential prerequisite for cell motility. Hence, we tested whether cells acquire motile properties when in contact with SBS fibres.

We initially chose dendritic cells due to their marked motility in vitro [45]. Dendritic cells were seeded for $24 \mathrm{~h}$ on SBS fibres and then observed at $37^{\circ} \mathrm{C}$ by phase contrast microscopy. Remarkably, dendritic cells actively moved on all types of SBS fibres regardless of fibre diameter (Fig. 5 and suppl. videos). Sometime we observed more than one dendritic cell moving along the same fibre (Fig. 5D and suppl. video). In addition, dendritic cells initially moving along one fibre sometime continued their movement on an adjacent fibre crossing the fibre where they initially moved (Fig. 5C and suppl. video). Under the same experimental conditions, we also found that also B16F1 cells move along the major axis of SBS fibres (suppl. data).

Because of the prominent motility of cells along SBS fibres, we hypothesised that actin and vinculin accumulation at cell-fibre interface is a dynamic rather than a static event. To test this hypothesis, used B16F1 cells stably expressing RFP-actin or RFPzyxin for monitoring the dynamics of actin cytoskeleton and focal adhesions, respectively. Twenty-four hours after seeding B16F1 cells on SBS fibres we analysed actin and zyxin dynamics by time-lapse fluorescence video microscopy. In line with the above results, we observed the redistribution of RFP-actin and RFPzyxin at cell-fibre interfaces (Fig. 6A, B). Remarkably, RFP-actin and RFP-zyxin at these locations were highly dynamic resulting in accumulation or disappearance of zones enriched in RFP-actin and RFP-zyxin along SBS fibres (Fig. 6A, B and suppl. videos). Together, these findings indicate that SBS fibres serve as effective tools for supporting cell motility.

\subsection{SBS fibres do not induce a mature phenotype in dendritic cells}

Although frequently used in clinical applications, some biomaterials induce immune reactions both in vitro and in vivo $[15,46]$. In this context, Toll-like receptors, plasma membrane and intracellular molecules used by dendritic cells to recognised pathogens, play a major role in biomaterial-dendritic cells interactions $[15,47]$. In light of the potential use of SBS fibres in clinical applications, we sought to determine whether they induced any change in dendritic cells biology. Dendritic cells functional state can be precisely defined based on two parameters: surface markers and cytokine expression levels. Precisely, immature dendritic cells express low levels of MHCII, very little or not co-stimulatory molecules (CD80, CD86 and CD40) and, usually, do not secrete cytokines (IL-6, IL-10, IL-12p70, RANTES, IL-1 $\beta$ and TNF $\alpha$ ). Upon stimulation, dendritic cells become mature expressing high levels of surface markers and cytokines.

We initially tested whether SBS fibres induce the expression of MHCII, CD80, CD86 and CD40. Untreated dendritic cells were exposed to SBS fibres for 24 or $48 \mathrm{~h}$. As positive control, dendritic cells were incubated with LPS, a bacterial cell wall component, for 24 or $48 \mathrm{~h}$. As shown in Fig. 7, DCs responded to LSP stimulation by increasing the expression of MHCII, CD80, CD86 and CD40 (Fig. 7A). Notably, none of the SBS fibres induced the up regulation of these surface markers those levels remained always below, or comparable to, the expression levels in untreated dendritic cells (Fig. 7A, B). Similar results were observed after $48 \mathrm{~h}$ incubation (Fig. 4SUP).

Next, we analysed the effect of SBS fibres on cytokine expression. After incubating dendritic cells with SBS fibres for $24 \mathrm{~h}$, cells were collected and the levels of IL-6, IL-10, IL-12p70, RANTES, IL-1 $\beta$ and TNF $\alpha$ were determined by RT-PCR. Also in this case, dendritic cells treated with LPS served as positive control. Consistent with the data for surface marker expression, the above cytokines were expressed only in LPS-treated cells $(p<0.0001)$, whereas their levels in dendritic cells incubated with SBS fibres were not significantly different from those in control, untreated cells (Fig. 8A, B). Collectively, these findings indicate that SBS fibres are immunological inert biomaterials making them particularly well suited for clinical applications.

\section{Discussion}

In this study, we have designed and fabricated polymeric fibres composed of PLA or various PLA/PEG blends using a simple and rapid solution blow spinning technique. We also showed that SBS 


\section{Dendritic cells}

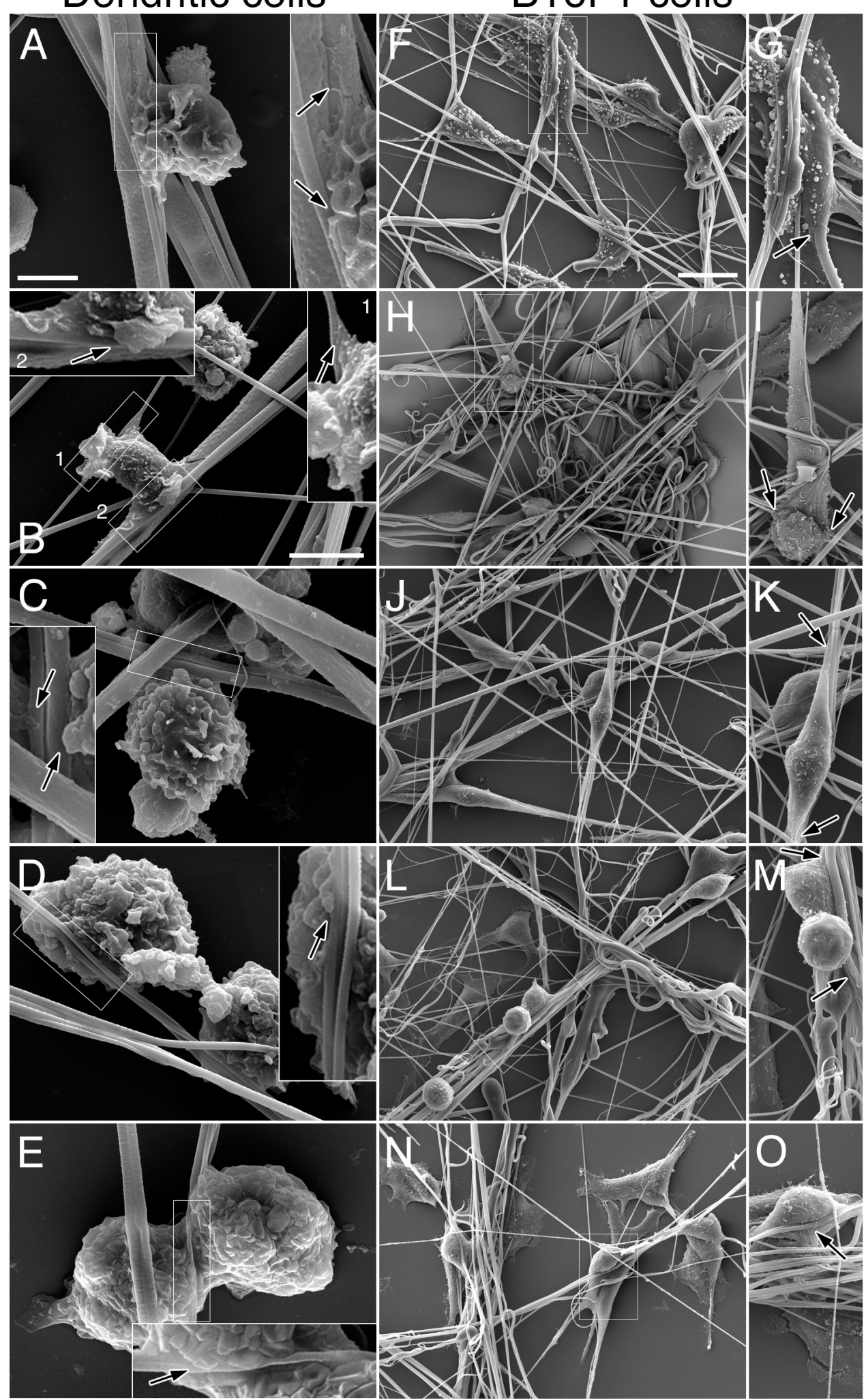

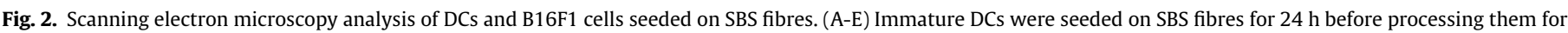

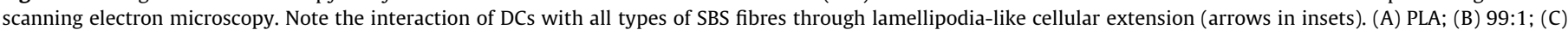

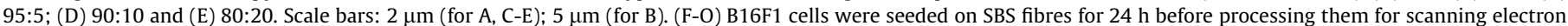

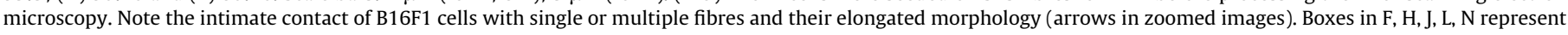
areas enlarged in G, I, K, M, O, respectively. (F) PLA; (H) 99:1; (J) 95:5; (L) 90:10; (N) 80:20. Scale bar: $2 \mu \mathrm{m}$. 


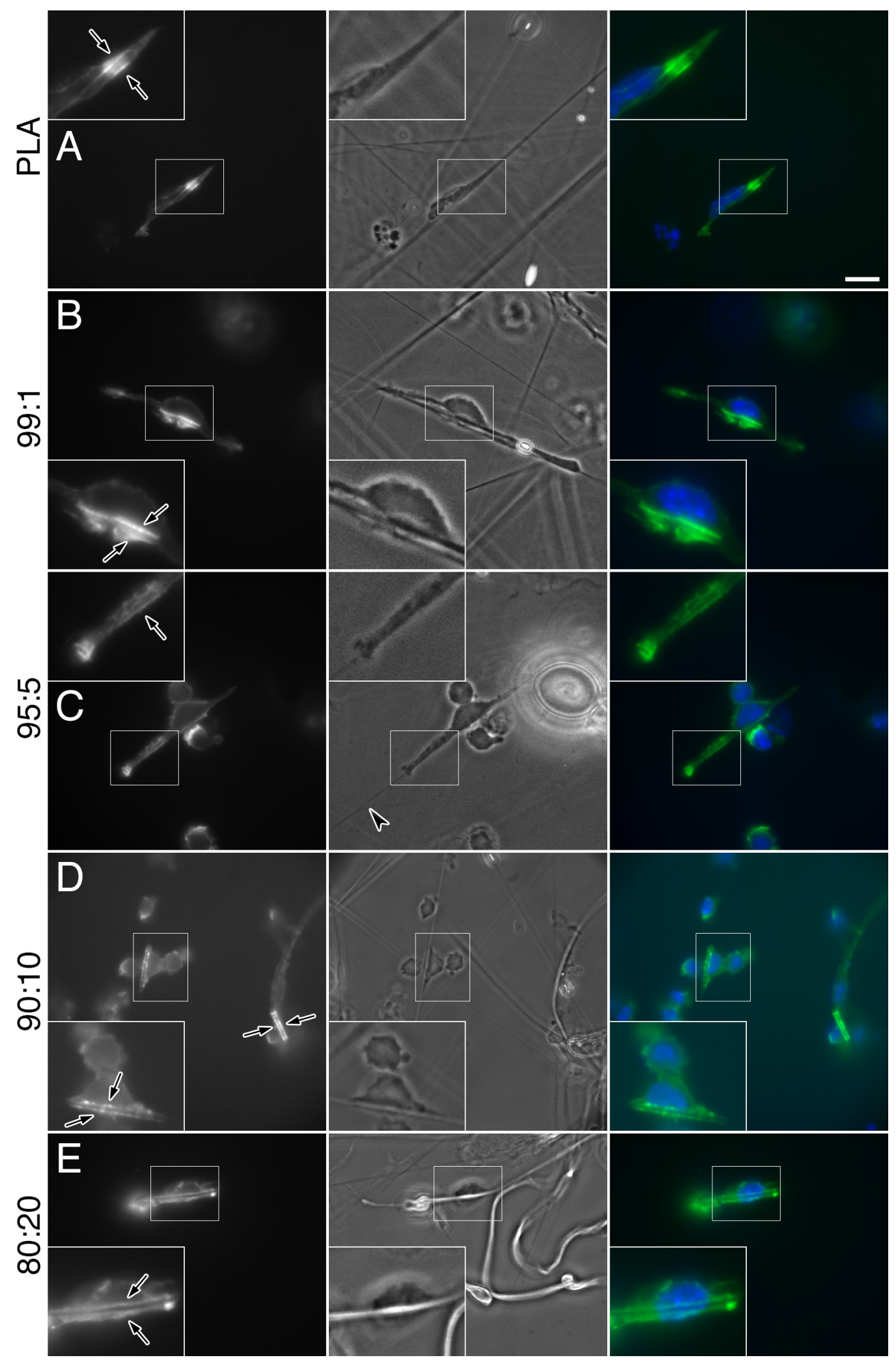

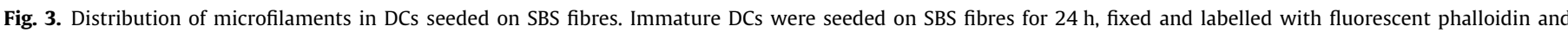





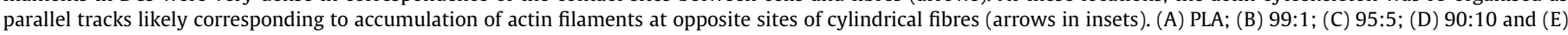
80:20. Scale bar: $10 \mu \mathrm{m}$.

fibres supported adhesion and motility of dendritic cells and B16F1 cells. Remarkably, SBS fibres did not substantially alter the biology of dendritic cells, which retained an immature phenotype after interaction with SBS fibres. Thus, based on our findings, we pro- 


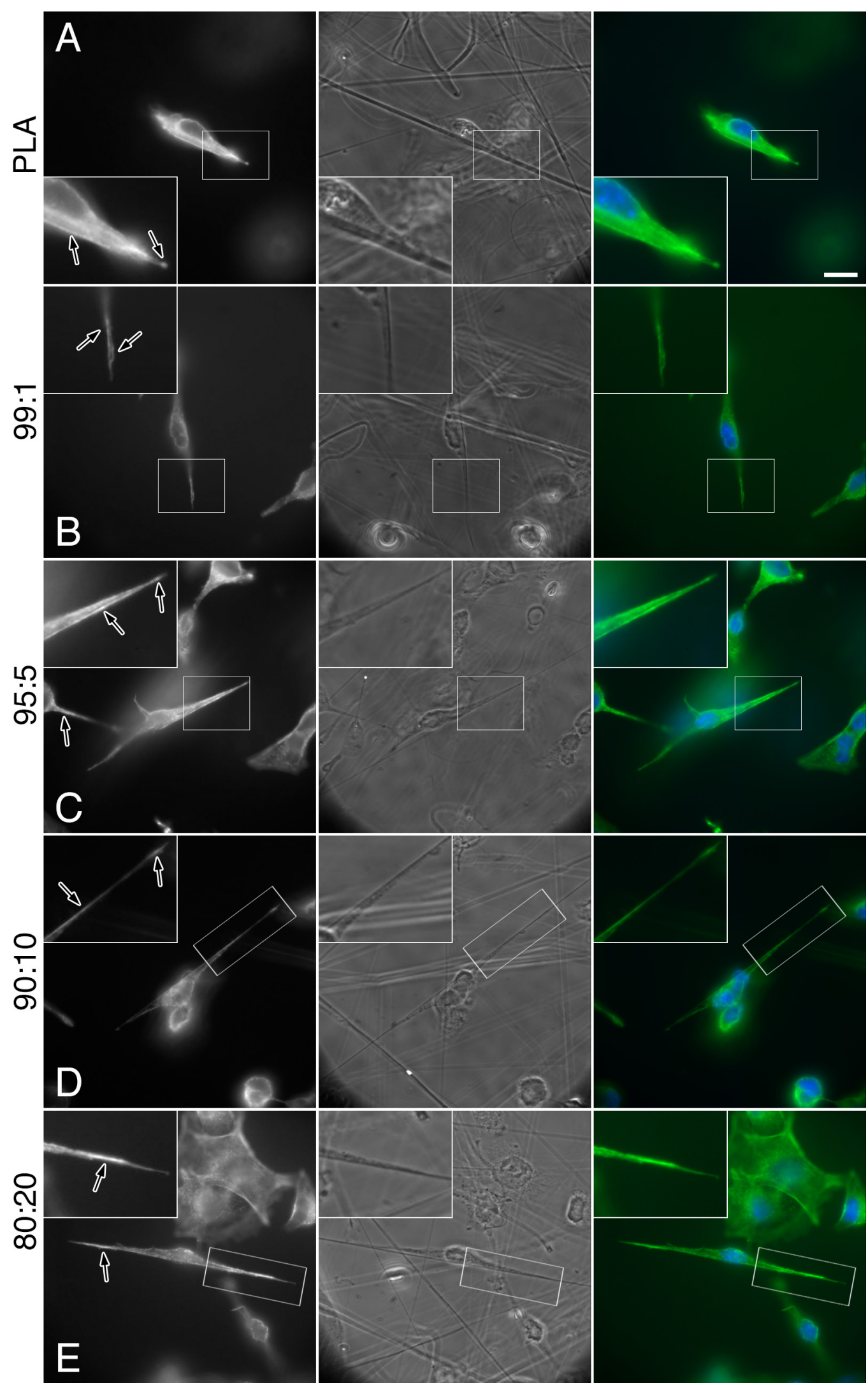

Fig. 4. Distribution of microfilaments in B16F1 cells in contact with SBS fibres. B16F1 cells were seeded on SBS fibres for $24 \mathrm{~h}$, fixed and labelled with fluorescent phalloidin and Hoechst. Left panels: actin labelling, middle panels: phase contrast images; right panels: actin/Hoechst merged images. Boxed areas correspond to enlarged images in insets. Note the intense actin accumulation at the contact sites between B16F1 cells and SBS fibres (arrows). (A) PLA; (B) 99:1; (C) 95:5; (D) 90:10 and (E) 80:20. Scale bar: $10 \mu \mathrm{m}$. 

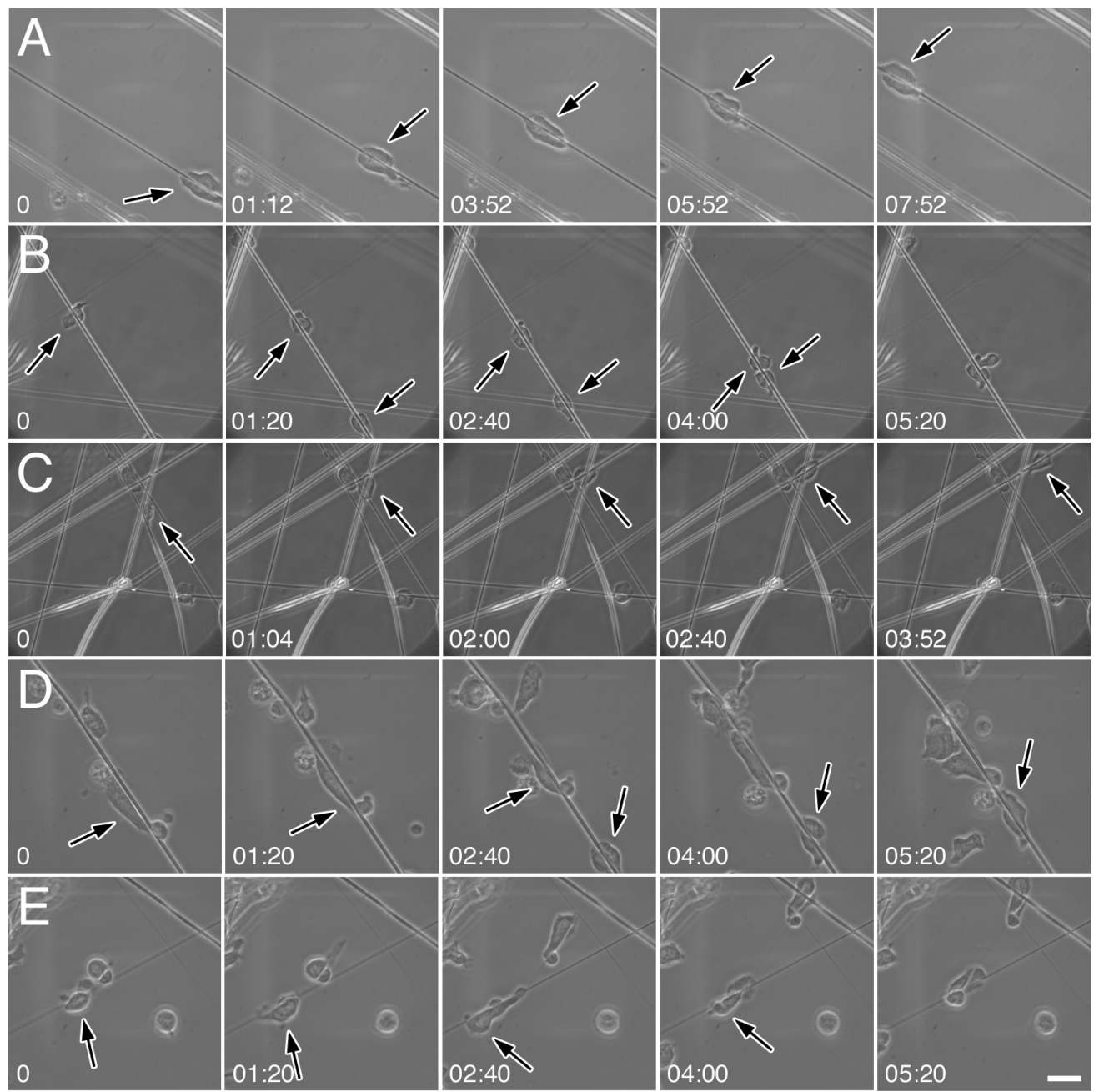

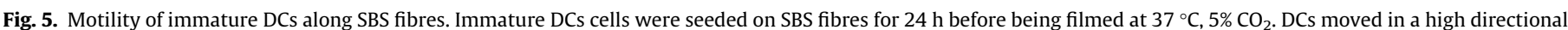

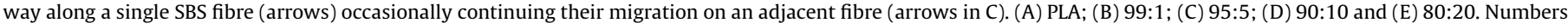
indicate elapsed time in minute and seconds. Scale bar: $10 \mu \mathrm{m}$.

pose that SBS fibres will serve as flexible, immunologically inert, biomaterials for clinical applications such as tissue regeneration that require the precise regulation of cell adhesion and migration.

It has been previously reported that incorporation of PEG in PLA solution not only facilitates the solution blow spinning process but also introduces structural and physico-chemical changes in SBS fibres [48]. Here, we showed that the incorporation of PEG in otherwise pure PLA fibres modified their physico-chemical and morphological properties. ATR-FTIR spectra of PLA/PEG blends showed a characteristic absorbance at $2880 \mathrm{~cm}^{-1}$ that can be attributed to $\mathrm{CH}$ stretching, a feature confirming the presence of PEG in these polymeric blends. Conceivably, the decrease of SBS fibre diameter produced from PLA/PEG blends was due to the low molecular weight of PEG, which caused a reduction of solution viscosity thus leading to faster polymer flow rates from the SBS nozzle and, hence, thinner fibres. Furthermore, increasing the ratio of PEG in PLA/PEG blends decreased the hydrophobicity of SBS fibres. The wettability of a surface reflects its surface chemistry and many studies have shown that enhancing the hydrophilic properties of polymers leads to increased cell spreading and adhesion [49-53]. It should also be noted that hydrophobic interactions have also been implicated in the interaction of cells with polymeric materials [54,55], highlighting the complexity of cell-material interactions. In this context, we propose that the increased hydrophobicity of SBS fibres incubated with culture media may facilitate their interaction with cells.

Despite the loss of a fraction of PEG from PLA/PEG SBS fibres incubated with physiological solutions, PEG was an essential component for improving PLA material processability and can be utilized to adjust polymer fibre degradation rates. The use of PEG as a plasticizer of PLA can promote reduction of the intermolecular force and increase the mobility of polymer chains, thereby improving flexibility, extensibility, resistance of fibre and scaffold quality [56]. In perspective, our ability to control more properties of SBS fibres will provide a flexible tool for development of biomaterials tailored to diverse clinical applications.

Several biological processes require a precise spatial and temporal regulation of cell migration. This is the case, for instance, of tissue regeneration during which several cell types must migrate into the healing tissue in a highly co-ordinated manner [57,58]. In this context, the development of biomaterials able to guide cell migration would greatly increase the efficiency of tissue regeneration. Several hurdles must be overcome to achieve such a feat. For example, biomaterials supporting cell migration should be designed in a way that supports the adhesion and motility of diverse cell types. This could be achieved by changing the chemistry of biomaterial surface via conjugation with extra cellular matrix proteins $[59,60]$. Furthermore, variation of size and topography could also be exploited to regulate cell migration. It is impor- 




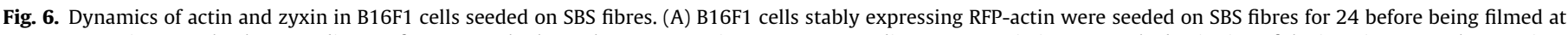

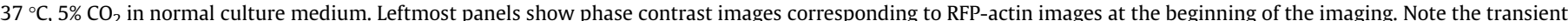

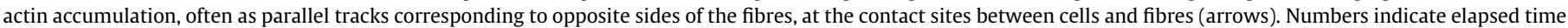

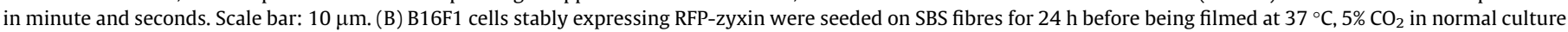

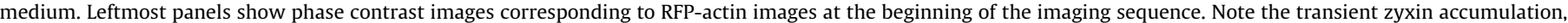
corresponding to focal adhesions, at the contact sites between cells and fibres (arrows). Numbers indicate elapsed time in minute and seconds. Scale bar: $10 \mu \mathrm{m}$.

tant to note, however, that the above biomaterial features are of little use if the biomaterial itself cannot be engineered in a form readily applicable to sites where tissue regeneration (and cell migration) is required. Given the ability to support the migration of cell types as diverse as dendritic cells and B16F1 and the ease of the manufacturing process (i.e. SBS fibre can be potentially arranged in many ways and deposited on any surface), we think that SBS fibres can serve as simple, yet elegant, tools to develop biomedical devices. From the point of view of understanding the molecular basis of cell adhesion and motility, the topography and geometric arrangement (both in two or three dimensions) of SBS fibres could be exploited to regulate cell adhesion and motility.
Moreover, in contrast to other systems in which cell migration is supported by materials anchored on rigid substrates (i.e. glass coverslips) [61], we envisage that SBS fibres could be arranged like the suspension spans of a bridge thus allowing a novel strategy for the analysis of cell motility and adhesion.

A major and still unsolved problem associated with the use of biomaterials in clinical applications is that they invariably induce an immune reaction at the site of implantation [62,63]. The molecular basis of this "host-versus-biomaterial" reaction is incompletely understood though some studies have shed a new light on this unwanted process $[15,64,65]$. Because of the fundamental role of dendritic cells in the regulation of immune response [42], 

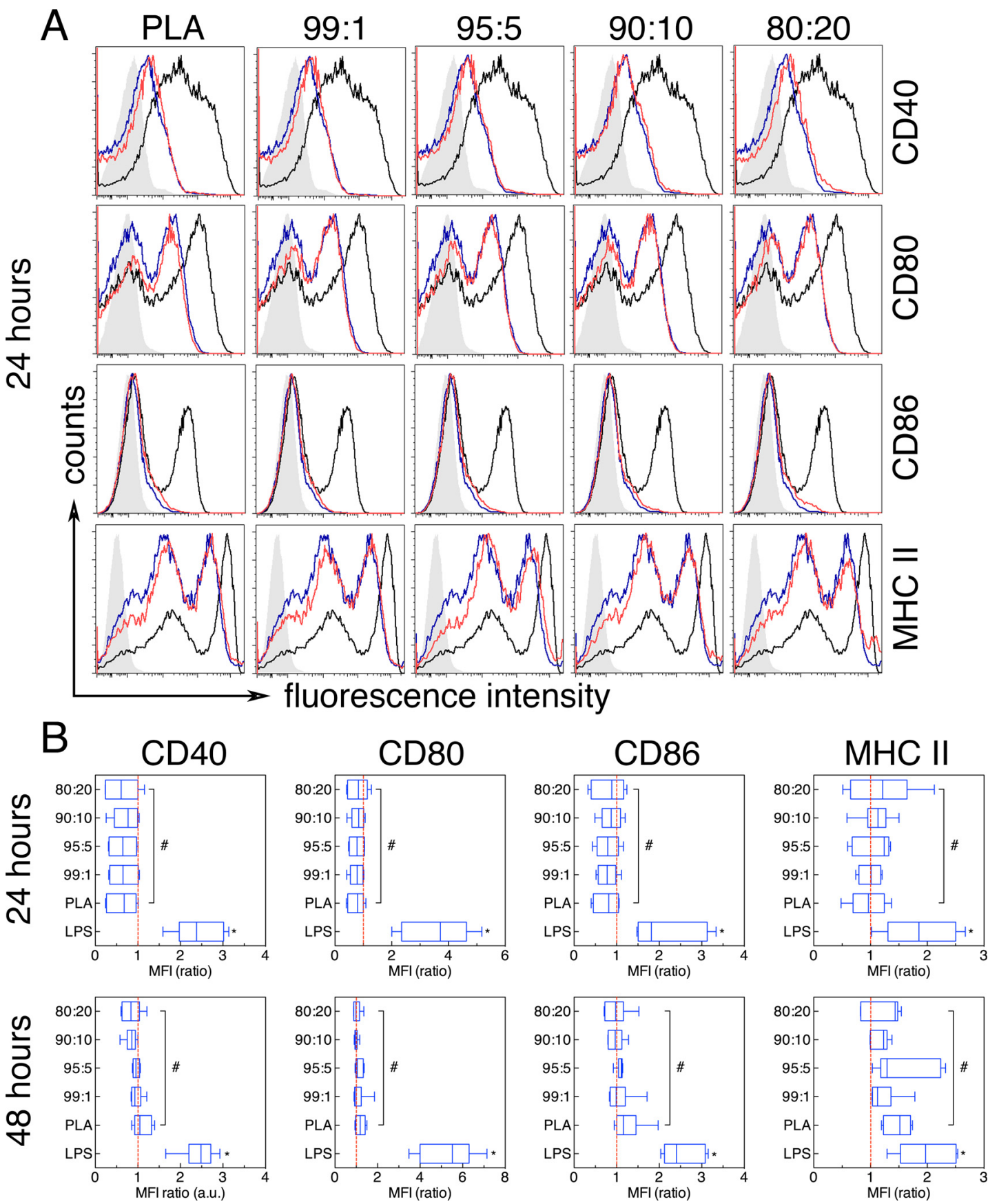

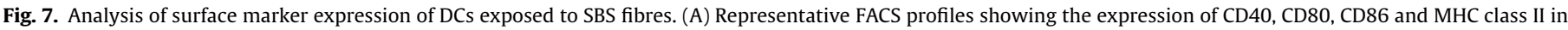

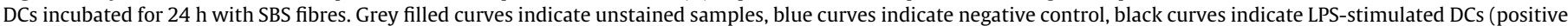



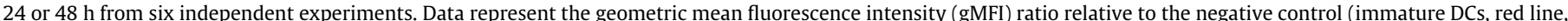

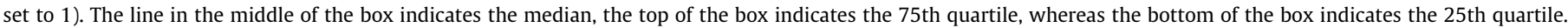

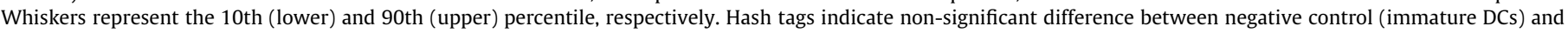
DCs exposed to SBS fibres. ${ }^{*} p<0.05$.

it is not surprising that these cells react to biomaterials. For instance, human and mouse dendritic cells secrete IL-6 and TNF$\alpha$ upon exposure to PLGA $[18,19]$. Furthermore, we observed a strong up regulation of surface markers and cytokines in dendritic cells exposed to alginate, LT706 and RG503 [15]. Interestingly, other polymers such as PDLLA, PET and PVDF do not induce substantial increase of surface markers and cytokines in murine dendritic cells [15]. Other studies on dendritic cells demonstrated that PLA and PEG induce little inflammatory response in these cells
[20]. Here, we showed that pure PLA fibres and fibres composed of various PLA/PEG blends do not induce up regulation of surface marker and cytokines in dendritic cells, which retained an immature phenotype. Thus, our findings suggest that SBS fibres could be particularly suitable for tissue engineering applications in light of the potentially minimal inflammatory reaction induced by these materials upon implantation.

We expect that our study will significantly contribute to both broadening our understanding of complex cell/material interac- 



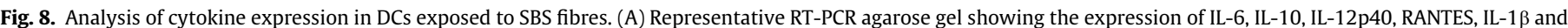

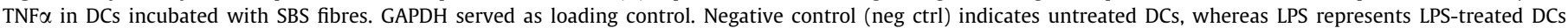

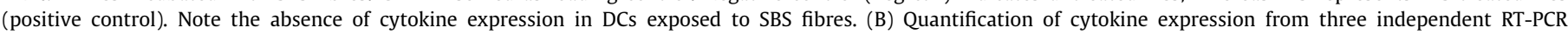

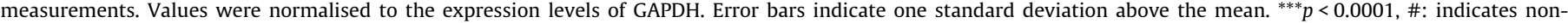
significant difference between negative control and DCs exposed to SBS fibres.

tions and developing of novel biomaterials aimed at tuning biological responses. We believe that our SBS fibres are highly adaptable polymers that can be easily engineered to achieve topographic and physico-chemical properties of choice to mimic native microenvironments required for regulation of cell function and fate.

\section{Acknowledgements}

This work was financially supported by São Paulo Research Foundation (FAPESP) grants (2015/00771-2 and 2013/03474-3), CNPq grants (402.287/2013-4 and 303.796/2014-6), MCT/SISNANO, Embrapa/Rede AgroNano - Brazil. This work was also partly supported by the Excellence Initiative of the German federal and state governments (Seed Funds programme, project OPSF363).

\section{Appendix A. Supplementary data}

Supplementary data associated with this article can be found, in the online version, at http://dx.doi.org/10.1016/j.actbio.2017.01. 020 .

\section{References}

[1] M. Shafiq, Y. Jung, S.H. Kim, Insight on stem cell preconditioning and instructive biomaterials to enhance cell adhesion, retention, and engraftment for tissue repair, Biomaterials 90 (2016) 85-115.

[2] T.H. Qazi, D.J. Mooney, M. Pumberger, S. Geissler, G.N. Duda, Biomaterials based strategies for skeletal muscle tissue engineering: existing technologies and future trends, Biomaterials 53 (2015) 502-521.

[3] J. Doshi, D.H. Reneker, Selected papers from the special technical session "Electrostatics in Polymer Processing and Charge Monitoring", 1993 IEEE Industry Applications Society MeetingElectrospinning process and applications of electrospun fibers, J. Electrostat. 35 (2) (1995) 151-160.

[4] E.S. Medeiros, G.M. Glenn, Solution blow spinning: a new method to produce micro-and nanofibers from polymer solutions, J. Appl. Polym. Sci. 113 (2009) $2322-2330$.

[5] R.M.d.C. Farias, R.R. Menezes, J.E. Oliveira, E.S. de Medeiros, Production of submicrometric fibers of mullite by solution blow spinning (SBS), Mater. Lett. 149 (2015) 47-49.

[6] J.E. Oliveira, L.H.C. Mattoso, W.J. Orts, Structural and morphological characterization of micro and nanofibers produced by electrospinning and solution blow spinning: a comparative study, Adv. Mater. Sci. Eng. 2013 (2013) $1-15$.

[7] R.F. Bonan, P.R.F. Bonan, A.U.D. Batista, F.C. Sampaio, A.J.R. Albuquerque, M.C.B. Moraes, L.H.C. Mattoso, G.M. Glenn, E.S. Medeiros, J.E. Oliveira, In vitro antimicrobial activity of solution blow spun poly(lactic acid)/ polyvinylpyrrolidone nanofibers loaded with Copaiba (Copaifera sp.) oil, Mater. Sci. Eng., C 48 (2015) 372-377.

[8] A.M. Behrens, J. Kim, N. Hotaling, J.E. Seppala, P. Kofinas, W. Tutak, Rapid fabrication of poly(DL-lactide) nanofiber scaffolds with tunable degradation for tissue engineering applications by air-brushing, Biomed. Mater. 11 (3) (2016) 035001.

[9] A.M. Behrens, N.G. Lee, B.J. Casey, P. Srinivasan, M.J. Sikorski, J.L. Daristotle, A.D. Sandler, P. Kofinas, Biodegradable-polymer-blend-based surgical sealant with body-temperature-mediated adhesion, Adv. Mater. Weinheim 27 (48) (2015) 8056-8061.

[10] W. Tutak, S. Sarkar, S. Lin-Gibson, T.M. Farooque, G. Jyotsnendu, D. Wang, J. Kohn, D. Bolikal, C.G. Simon Jr., The support of bone marrow stromal cell differentiation by airbrushed nanofiber scaffolds, Biomaterials 34 (10) (2013) 2389-2398.

[11] S. Yuan, Z. Li, L. Song, H. Shi, S. Luan, J. Yin, Liquid-infused poly(styrene-bisobutylene-b-styrene) microfiber coating prevents bacterial attachment and thrombosis, ACS Appl. Mater. Interface 8 (33) (2016) 21214-21220.

[12] S. Di Cio, J.E. Gautrot, Cell sensing of physical properties at the nanoscale: mechanisms and control of cell adhesion and phenotype, Acta Biomater. 30 (2016) 26-48.

[13] S. Neuss, C. Apel, P. Buttler, B. Denecke, A. Dhanasingh, X. Ding, D. Grafahrend, A. Groger, K. Hemmrich, A. Herr, W. Jahnen-Dechent, S. Mastitskaya, A. PerezBouza, S. Rosewick, J. Salber, M. Woltje, M. Zenke, Assessment of stem cell/ biomaterial combinations for stem cell-based tissue engineering, Biomaterials 29 (3) (2008) 302-313.

[14] S. Neuss, B. Denecke, L. Gan, Q. Lin, M. Bovi, C. Apel, M. Woltje, A. Dhanasingh, J. Salber, R. Knuchel, M. Zenke, Transcriptome analysis of MSC and MSCderived osteoblasts on Resomer(R) LT706 and PCL: impact of biomaterial substrate on osteogenic differentiation, PLoS ONE 6 (9) (2011) e23195.

[15] B. Shokouhi, C. Coban, V. Hasirci, E. Aydin, A. Dhanasingh, N. Shi, S. Koyama, S. Akira, M. Zenke, A.S. Sechi, The role of multiple toll-like receptor signalling cascades on interactions between biomedical polymers and dendritic cells, Biomaterials 31 (22) (2010) 5759-5771.

[16] G. Abagnale, M. Steger, V.H. Nguyen, N. Hersch, A. Sechi, S. Joussen, B. Denecke, R. Merkel, B. Hoffmann, A. Dreser, U. Schnakenberg, A. Gillner, W. Wagner, Surface topography enhances differentiation of mesenchymal stem cells towards osteogenic and adipogenic lineages, Biomaterials 61 (2015) 316-326.

[17] A. Sechi, J.M.G. Freitas, P. Wünnemann, A. Töpel, R.T. Paschoalin, S. Ullmann, R. Schröder, G. Aydin, S. Rütten, A. Böker, M. Zenke, A. Pich, Surface-grafted nanogel arrays direct cell adhesion and motility, Adv. Mater. Interfaces 3 (20) (2016) 1600455.

[18] M. Yoshida, J.E. Babensee, Poly(lactic-co-glycolic acid) enhances maturation of human monocyte-derived dendritic cells, J. Biomed. Mater. Res., Part A 71 (1) (2004) 45-54.

[19] J.E. Babensee, A. Paranjpe, Differential levels of dendritic cell maturation on different biomaterials used in combination products, J. Biomed. Mater. Res., Part A 74 (4) (2005) 503-510.

[20] M. Yoshida, J.E. Babensee, Differential effects of agarose and poly(lactic-coglycolic acid) on dendritic cell maturation, J. Biomed. Mater. Res., Part A 79 (2) (2006) 393-408.

[21] M. Yoshida, J. Mata, J.E. Babensee, Effect of poly(lactic-co-glycolic acid) contact on maturation of murine bone marrow-derived dendritic cells, J. Biomed. Mater. Res., Part A 80 (1) (2007) 7-12.

[22] H. Zhu, F. Yang, B. Tang, X.M. Li, Y.N. Chu, Y.L. Liu, S.G. Wang, D.C. Wu, Y. Zhang, Mesenchymal stem cells attenuated PLGA-induced inflammatory responses by inhibiting host DC maturation and function, Biomaterials 53 (2015) 688-698.

[23] L.A. Forato, R. Bernardes-Filho, L.A. Colnago, Protein structure in KBr pellets by infrared spectroscopy, Anal. Biochem. 259 (1) (1998) 136-141.

[24] D. Henton, P. Gruber, J. Lunt, J. Randall, Polylactic Acid Technology, Natural Fibers, Biopolymers, and Biocomposites, CRC Press, 2005, pp. 527-578. 
[25] I. Gamper, D. Fleck, M. Barlin, M. Spehr, S.E. Sayad, H. Kleine, S. Maxeiner, C. Schalla, G. Aydin, M. Hoss, D.W. Litchfield, B. Luscher, M. Zenke, A. Sechi, GAR22beta regulates cell migration, sperm motility, and axoneme structure, Mol. Biol. Cell 27 (2) (2016) 277-294.

[26] S. Maxeiner, N. Shi, C. Schalla, G. Aydin, M. Hoss, S. Vogel, M. Zenke, A.S. Sechi, Crucial role for the LSP1-myosin1e bimolecular complex in the regulation of Fcgamma receptor-driven phagocytosis, Mol. Biol. Cell 26 (9) (2015) 16521664.

[27] M. Haeri, M. Haeri, ImageJ plugin for analysis of porous Scaffolds used in tissue engineering, J. Open Res. Softw. 3 (21) (2015) 4830.

[28] S. Pust, H. Morrison, J. Wehland, A.S. Sechi, P. Herrlich, Listeria monocytogenes exploits ERM protein functions to efficiently spread from cell to cell, EMBO J. 24 (6) (2005) 1287-1300.

[29] L.T. Choong, P. Yi, G.C. Rutledge, Three-dimensional imaging of electrospun fiber mats using confocal laser scanning microscopy and digital image analysis, J. Mater. Sci. 50 (8) (2015) 3014-3030.

[30] M. Ziabari, V. Mottaghitalab, A.K. Haghi, Evaluation of electrospun nanofiber pore structure parameters, Korean J. Chem. Eng. 25 (4) (2008) 923-932.

[31] K.J. Zhu, L. Xiangzhou, Y. Shilin, Preparation, characterization, and properties of polylactide (PLA)-poly(ethylene glycol) (PEG) copolymers: a potential drug carrier, J. Appl. Polym. Sci. 39 (1) (1990) 1-9.

[32] M. Sheth, R.A. Kumar, V. Davé, R.A. Gross, S.P. McCarthy, Biodegradable polymer blends of poly(lactic acid) and poly(ethylene glycol), J. Appl. Polym. Sci. 66 (8) (1997) 1495-1505.

[33] B.Y. Wang, S.Z. Fu, P.Y. Ni, J.R. Peng, L. Zheng, F. Luo, H. Liu, Z.Y. Qian, Electrospun polylactide/poly(ethylene glycol) hybrid fibrous scaffolds for tissue engineering, J. Biomed. Mater. Res., Part A 100 (2) (2012) 441-449.

[34] T. Nazari, H. Garmabi, Polylactic acid/polyethylene glycol blend fibres prepared via melt electrospinning: effect of polyethylene glycol content, IET Micro Nano Lett. 9 (10) (2014) 686-690.

[35] A. Toncheva, R. Mincheva, M. Kancheva, N. Manolova, I. Rashkov, P. Dubois, N. Markova, Antibacterial PLA/PEG electrospun fibers: comparative study between grafting and blending PEG, Eur. Polymer J. 75 (2016) 223-233.

[36] S. Jacobsen, H.G. Fritz, Plasticizing polylactide-the effect of different plasticizers on the mechanical properties, Polym. Eng. Sci. 39 (7) (1999) 1303-1310.

[37] Z. Kulinski, E. Piorkowska, Crystallization, structure and properties of plasticized poly(l-lactide), Polymer 46 (23) (2005) 10290-10300.

[38] J.B. McCarthy, L.T. Furcht, Laminin and fibronectin promote the haptotactic migration of B16 mouse melanoma cells in vitro, J. Cell Biol. 98 (4) (1984) 1474-1480.

[39] G. Liang, M. Ding, H. Lu, N.A. Cao, Y. Niu, Y. Gao, J. Lu, Metformin upregulates Ecadherin and inhibits B16F10 cell motility, invasion and migration, Oncol. Lett. 10 (3) (2015) 1527-1532.

[40] B.G. Ricart, M.T. Yang, C.A. Hunter, C.S. Chen, D.A. Hammer, Measuring traction forces of motile dendritic cells on micropost arrays, Biophys. J . 101 (11) (2011) $2620-2628$.

[41] A. Moretta, Natural killer cells and dendritic cells: rendezvous in abused tissues, Nat. Rev. Immunol. 2 (12) (2002) 957-964.

[42] M. Merad, P. Sathe, J. Helft, J. Miller, A. Mortha, The dendritic cell lineage: ontogeny and function of dendritic cells and their subsets in the steady state and the inflamed setting, Annu. Rev. Immunol. 31 (2013) 563-604.

[43] S.R.K. Vedula, M.C. Leong, T.L. Lai, P. Hersen, A.J. Kabla, C.T. Lim, B. Ladoux, Emerging modes of collective cell migration induced by geometrical constraints, Proc. Natl. Acad. Sci. 109 (32) (2012) 12974-12979.

[44] S. Huda, D. Pilans, M. Makurath, T. Hermans, K. Kandere-Grzybowska, B.A. Grzybowski, Microfabricated systems and assays for studying the cytoskeletal organization, micromechanics, and motility patterns of cancerous cells, Adv. Mater. Interfaces 1 (7) (2014).

[45] D.C. Shutt, K.J. Daniels, E.J. Carolan, A.C. Hill, D.R. Soll, Changes in the motility, morphology, and F-actin architecture of human dendritic cells in an in vitro model of dendritic cell development, Cell Motil. Cytoskelet. 46 (3) (2000) 200221.

[46] A.G. Mikos, L.V. McIntire, J.M. Anderson, J.E. Babensee, Host response to tissue engineered devices, Adv. Drug Deliv. Rev. 33 (1-2) (1998) 111-139.

[47] J.E. Babensee, Interaction of dendritic cells with biomaterials, Semin. Immunol. 20 (2) (2008) 101-108.

[48] H. Otsuka, Y. Nagasaki, K. Kataoka, Dynamic wettability study on the functionalized PEGylated layer on a polylactide surface constructed by the coating of aldehyde-ended poly(ethylene glycol) (PEG)/polylactide (PLA) block copolymer, Sci. Technol. Adv. Mater. 1 (1) (2000) 21-29.

[49] J.H. Lee, H.B. Lee, A wettability gradient as a tool to study protein adsorption and cell adhesion on polymer surfaces, J. Biomater. Sci. Polym. Ed. 4 (5) (1993) 467-481.

[50] L.T. Allen, M. Tosetto, I.S. Miller, D.P. O’Connor, S.C. Penney, I. Lynch, A.K Keenan, S.R. Pennington, K.A. Dawson, W.M. Gallagher, Surface-induced changes in protein adsorption and implications for cellular phenotypic responses to surface interaction, Biomaterials 27 (16) (2006) 3096-3108.

[51] D. Barata, C. van Blitterswijk, P. Habibovic, High-throughput screening approaches and combinatorial development of biomaterials using microfluidics, Acta Biomater. 34 (2016) 1-20.

[52] F.M. Chen, X. Liu, Advancing biomaterials of human origin for tissue engineering, Prog. Polym. Sci. 53 (2016) 86-168.

[53] R. Tzoneva, N. Faucheux, T. Groth, Wettability of substrata controls cellsubstrate and cell-cell adhesions, Biochim. Biophys. Acta 1770 (11) (2007) 1538-1547.

[54] H. Liu, X. Liu, J. Meng, P. Zhang, G. Yang, B. Su, K. Sun, L. Chen, D. Han, S. Wang, L. Jiang, Hydrophobic interaction-mediated capture and release of cancer cells on thermoresponsive nanostructured surfaces, Adv. Mater. 25 (6) (2013) 922 927.

[55] Y. Li, Y. Wei, J. Liao, Y. Hao, C. Ning, L. Jiang, S. Wang, Surface wettability switched cell adhesion and detachment on conducting polymer nanoarray, Adv. Mater. Interfaces 3 (19) (2016). 1600598-4.

[56] S. Andjelić, R.C. Scogna, Polymer crystallization rate challenges: the art of chemistry and processing, J. Appl. Polym. Sci. 42066 (38) (2015), http://dx.doi. org/10.1002/app.42066.

[57] H.J. Anders, P. Romagnani, A. Mantovani, Pathomechanisms: homeostatic chemokines in health, tissue regeneration, and progressive diseases, Trends Mol. Med. 20 (3) (2014) 154-165.

[58] L.P. Kamolz, M. Keck, C. Kasper, Wharton's jelly mesenchymal stem cells promote wound healing and tissue regeneration, Stem Cell Res. Ther. 5 (3) (2014) 62.

[59] D. Grafahrend, K.H. Heffels, M.V. Beer, P. Gasteier, M. Moller, G. Boehm, P.D Dalton, J. Groll, Degradable polyester scaffolds with controlled surface chemistry combining minimal protein adsorption with specific bioactivation, Nat. Mater. 10 (1) (2011) 67-73.

[60] A.A. Khalili, M.R. Ahmad, A review of cell adhesion studies for biomedical and biological applications, Int. J. Mol. Sci. 16 (8) (2015) 18149-18184.

[61] C. Guetta-Terrier, P. Monzo, J. Zhu, H. Long, L. Venkatraman, Y. Zhou, P. Wang, S.Y. Chew, A. Mogilner, B. Ladoux, N.C. Gauthier, Protrusive waves guide 3D cell migration along nanofibers, J. Cell Biol. 211 (3) (2015) 683-701.

[62] J.M. Anderson, A. Rodriguez, D.T. Chang, Foreign body reaction to biomaterials, Semin. Immunol. 20 (2) (2008) 86-100.

[63] W. Kenneth Ward, A review of the foreign-body response to subcutaneouslyimplanted devices: the role of macrophages and cytokines in biofouling and fibrosis, J. Diabetes Sci. Technol. 2 (5) (2008) 768-777.

[64] B.G. Keselowsky, A.W. Bridges, K.L. Burns, C.C. Tate, J.E. Babensee, M.C. LaPlaca, A.J. García, Role of plasma fibronectin in the foreign body response to biomaterials, Biomaterials 28 (25) (2007) 3626.

[65] T.H. Rogers, J.E. Babensee, The role of integrins in the recognition and response of dendritic cells to biomaterials, Biomaterials 32 (5) (2011) 1270-1279. 